\title{
Tracking long-distance migration of marine fish using compound-specific stable isotope analysis of amino acids
}

\author{
Jun Matsubayashi $^{1}$, Yutaka Osada ${ }^{1}$, Kazuaki Tadokoro ${ }^{2}$, Yoshiyuki Abe ${ }^{3}$, Atsushi \\ Yamaguchi $^{4}$, Kotaro Shirai ${ }^{5}$, Kentaro Honda ${ }^{6}$, Chisato Yoshikawa ${ }^{7}$, Nanako Ogawa ${ }^{7}$, \\ Naohiko Ohkouchi ${ }^{8}$, Naoto Ishikawa ${ }^{7}$, Toshi Nagata ${ }^{3}$, Hiroomi Miyamoto ${ }^{2}$, Shigeto \\ Nishino $^{7}$, and Ichiro Tayasu ${ }^{1}$ \\ ${ }^{1}$ Research Institute for Humanity and Nature \\ ${ }^{2}$ Tohoku National Fisheries Research Institute \\ ${ }^{3}$ The University of Tokyo Atmosphere and Ocean Research Institute \\ ${ }^{4}$ Hokkaido University Faculty of Fisheries Sciences Graduate School of Fisheries Sciences \\ School of Fisheries Sciences \\ ${ }^{5}$ University of Tokyo Atmosphere and Ocean Research Institute \\ ${ }^{6}$ Hokkaido National Fisheries Research Institute Fisheries Research Agency \\ ${ }^{7}$ Japan Agency for Marine-Earth Science and Technology \\ ${ }^{8}$ Japan Agency for Marine-Earth Science \& Technology
}

April 28, 2020

\begin{abstract}
Long-distance migrations by marine fish have long fascinated scientists, but are difficult to track by visual surveys. Here, we propose a new method to easily and precisely track such migrations using stable nitrogen isotopic composition at the base of the food web $\left(\delta^{15} \mathrm{~N}_{\text {Base }}\right)$, which can be estimated by using compound-specific isotope analysis. $\delta^{15} \mathrm{~N}_{\text {Base }}$ exclusively reflects the $\delta^{15} \mathrm{~N}$ of nitrate in the ocean at a regional scale and is not affected by the trophic position of sampled organisms. We initially constructed a $\delta^{15} \mathrm{~N}_{\text {Base }}$ isoscape in the northern North Pacific, and determined retrospective $\delta^{15} \mathrm{~N}_{\text {Base }}$ values of chum salmon (Oncorhynchus keta) from their vertebral centra. Then, we estimated the migration routes of chum salmon during their skeletal growth by using a state-space model. Our isotope tracking method successfully reproduced a known chum salmon migration route between the Okhotsk and Bering seas, and indicates the presence of a novel migration route to the eastern Bering Sea Shelf during a later growth stage.
\end{abstract}

\section{Hosted file}

Isotope tracking 191115.pdf available at https://authorea.com/users/285382/articles/409269-trackinglong-distance-migration-of-marine-fish-using-compound-specific-stable-isotope-analysis-ofamino-acids

\section{Figure legends}

Fig. 1. Map of the estimated $\delta 15 \mathrm{NBase}$ isoscape showing the location of zooplankton sampling sites (white circles).

Fig. 2. Patterns in $\delta 15$ NBulk along the vertebral sections of sampled Japanese chum salmon (IDs: OK1-8). 
Vertebral bone sections ( $x$-axis) are numbered from the center of the vertebral centrum and increase toward the margin.

Fig. 3. Estimated chum salmon migration areas. Mean presence probabilities for two salmon individuals (IDs: OK2 and OK8) at growth stages 1-10 (panels 1-10, respectively). The color gradients (tints of orange) indicate presence probability (low to high). The grey area shows the extent of the isoscape.
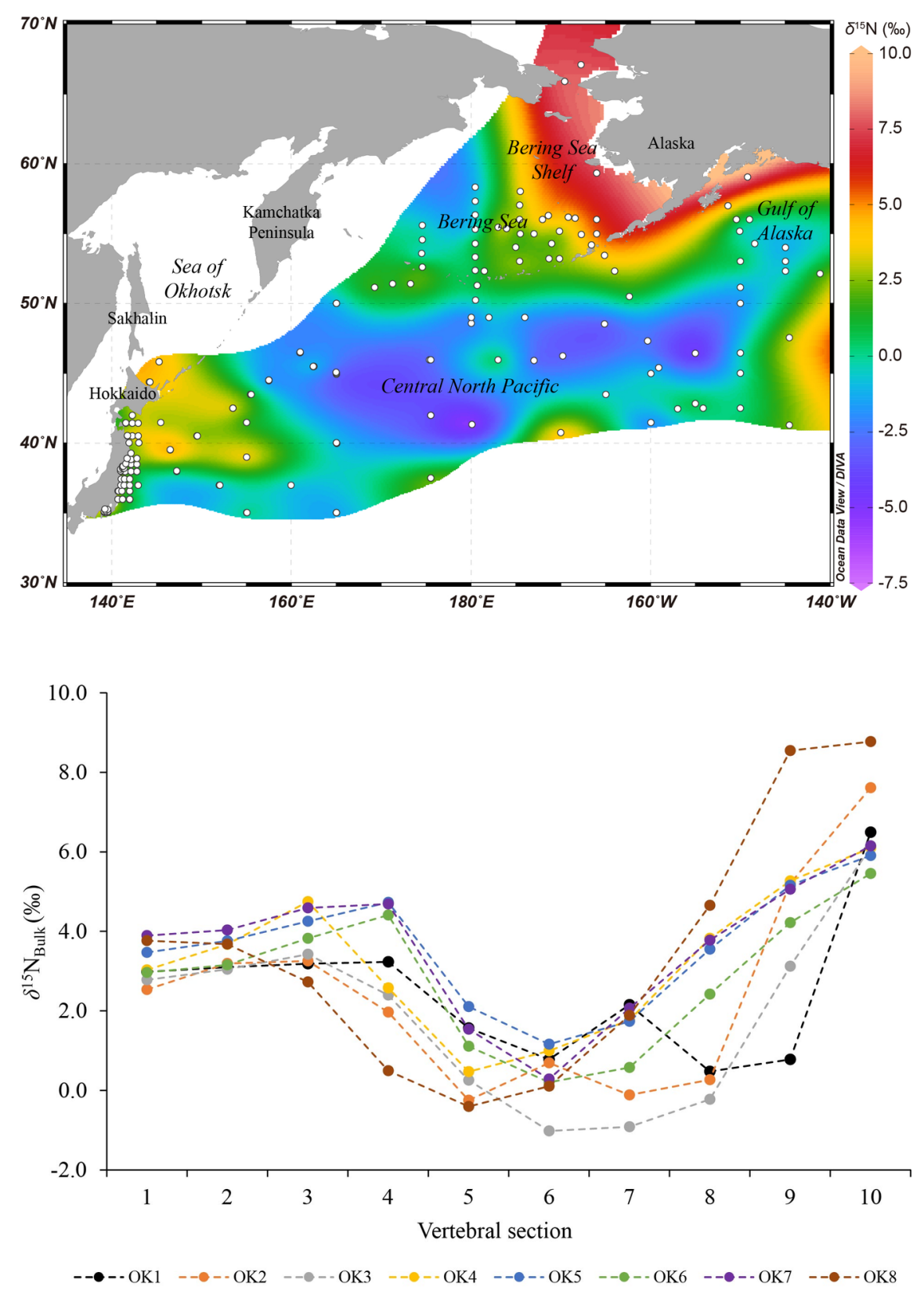


\section{ID: OK2}

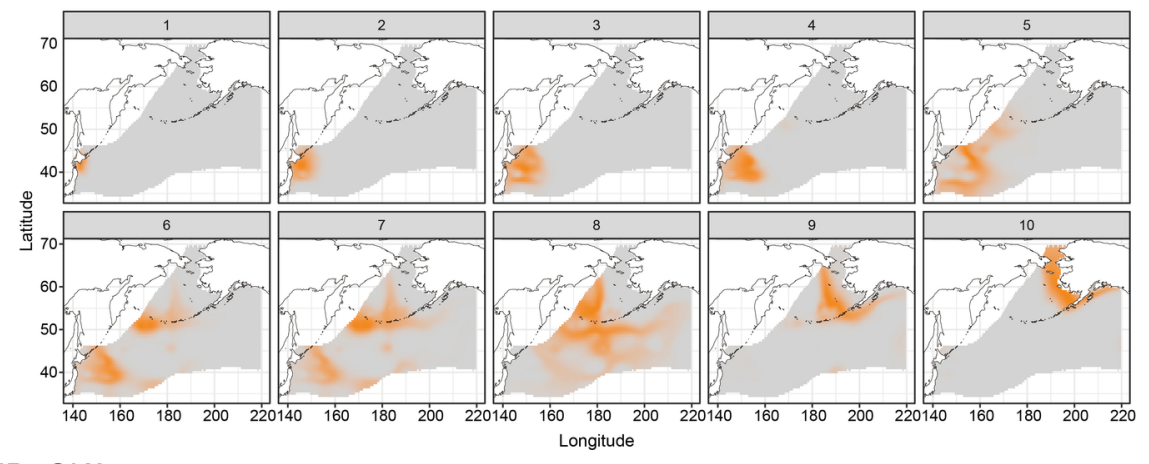

ID: OK8

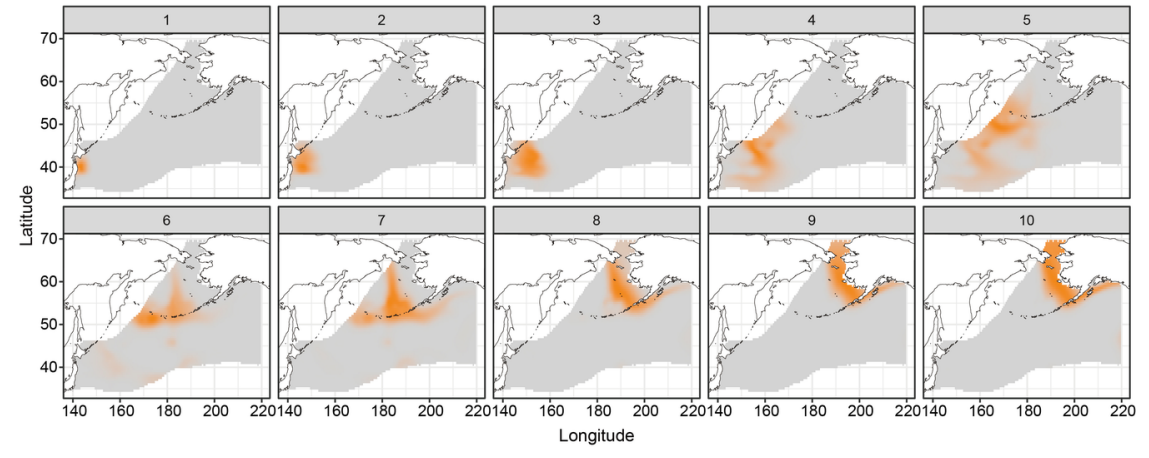

